\title{
Reporte de caso ¿publicado en dos revistas?
}

\section{Case report, published in two journals?}

\author{
Hugo Arroyo-Hernández ${ }^{1}$ Renatta Quijano-Escate ${ }^{2}$
}

\author{
1 Oficina General de Información y Sistemas, Instituto Nacional de \\ Salud, Lima, Perú \\ ${ }^{2}$ Sociedad Científica de Estudiantes de Medicina de Ica, Facultad de \\ Medicina, Universidad Nacional San Luis Gonzaga, Ica, Perú
}

Urol Colomb 2020;29:176-177.

Dear Editor,

En el volumen 28, número 1 del 2019 de la revista Urología Colombiana se publicó el artículo titulado "Dolor abdominal agudo secundario a la rotura de tumor de Wilms: reporte de caso", el mismo que haciendo una búsqueda en Google presenta similar contenido al publicado en otra revista. En la - Tabla 1 se describen las similitudes en el paciente encontradas en los resúmenes de las dos revistas.

Según el Comité Internacional de Editores de Revistas Médicas (ICMJE) una publicación duplicada se superpone con otro publicado sin una referencia a la publicación anterior, donde existe un autor común en ambas publicaciones, asî como similar muestra, metodología y resultados, o no se aporta nueva información. ${ }^{1}$ Si bien estos criterios son en principio usados para artículos originales, también se podrían aplicar a los reportes de casos. ${ }^{2}$

Las revistas científicas solicitan a los autores que el contenido de las contribuciones que reciben no se haya enviado para evaluación al mismo tiempo o publicado en otra revista, por lo tanto, debe ser original e inédito. Sin embargo, estos casos podrían suceder por una mala comunicación entre autores y decidir de forma separada su envió para publicación a dos revistas, o por el envió a una primera revista que no brinda adecuada comunicación a los autores sobre el proceso editorial del manuscrito recibido, así como también por un intento de evaluar que revista podría aceptar primero la publicación.

Si bien, las revistas científicas tienen procesos que buscan detectar a tiempo un posible intento de doble envío, a veces una publicación sin mayor visibilidad en bases de datos académicas o un periodo cercano de tiempo dónde las dos publicaciones se dan a conocer, podrían no permitir encontrar la duplicación del contenido. Ante el hallazgo de estos casos el editor solicita una explicación a los autores y de confirmarse una duplicación las revistas deben evaluar las
Address for correspondence Hugo Arroyo Hernández, Instituto Nacional de Salud., Cápac Yupanqui 1400. Jesús María. Lima, Perú (email: hugoarroyo2007@gmail.com).

acciones sobre el artículo, en base a los procesos establecidos por el Comité de Ética en Publicación (COPE). ${ }^{3}$

Como en otros casos se trata de un contenido similar en dos revistas científicas dónde una de ellas tiene menor visibilidad e indexación, ${ }^{2}$ esto podría originar la creencia por algunos autores que la publicación en estas revistas no cuenta y no se estaría cometiendo una publicación duplicada, siendo esto no considerable, debido a que ambas publicaciones podrían ser citables en otros manuscritos y que además muestra un desconocimiento o falta a los criterios de originalidad que se solicitan en las instrucciones de las revistas.

A esto debemos sumar la necesidad de algunas instituciones de dar visibilidad a sus publicaciones editando revistas científicas, pero que ameritan una mayor y más clara comunicación con sus autores y comunidad académica, sobre los criterios de originalidad en los manuscritos que reciben. Es probable que estos casos se sigan repitiendo en diversas revistas de Latinoamérica, siendo necesaria la identificación y comunicación de estos casos, para que tanto editores y lectores generen conciencia sobre estos problemas.

Conflicto de Intereses

los autores declaran no tener ningún conflicto de intereses.

\section{Referencias}

1 Kumar AS, Beyersdorf F, Denniss AR, Lazar HL, Patterson GA, Weisel RD. Joint statement on redundant (duplicate) publication by the Editors of the undersigned cardio-thoracic journals. Eur J Cardiothorac Surg 2015;48(03):343-343

2 Romaní F, Alarco JJ, Arroyo-Hernández H. Publicación duplicada de un reporte de caso. Rev Peru Med Exp Salud Publica 2018;35 (02):356-358. Doi: 10.17843/rpmesp.2018.352.3664

3 Committee Of Publication Ethics. What to do if you suspect redundant (duplicate) publication [documento en Internet]. London: COPE; 2008. [consultado: 16-04-2019]. Disponible en: http://publicationethics.org/files/u2/01B_Redundant_Published.pdf received

October 28, 2019

accepted

August 20, 2020
DOI https://doi.org/

10.1055/s-0040-1716860.

ISSN 0120-789X.

e ISSN 2027-0119.
Copyright (c) 2020, Sociedad Colombiana License terms de Urología. Publicado por Thieme Revinter Publicações Ltda., Rio de Janeiro, Brazil. Todos los derechos reservados. 


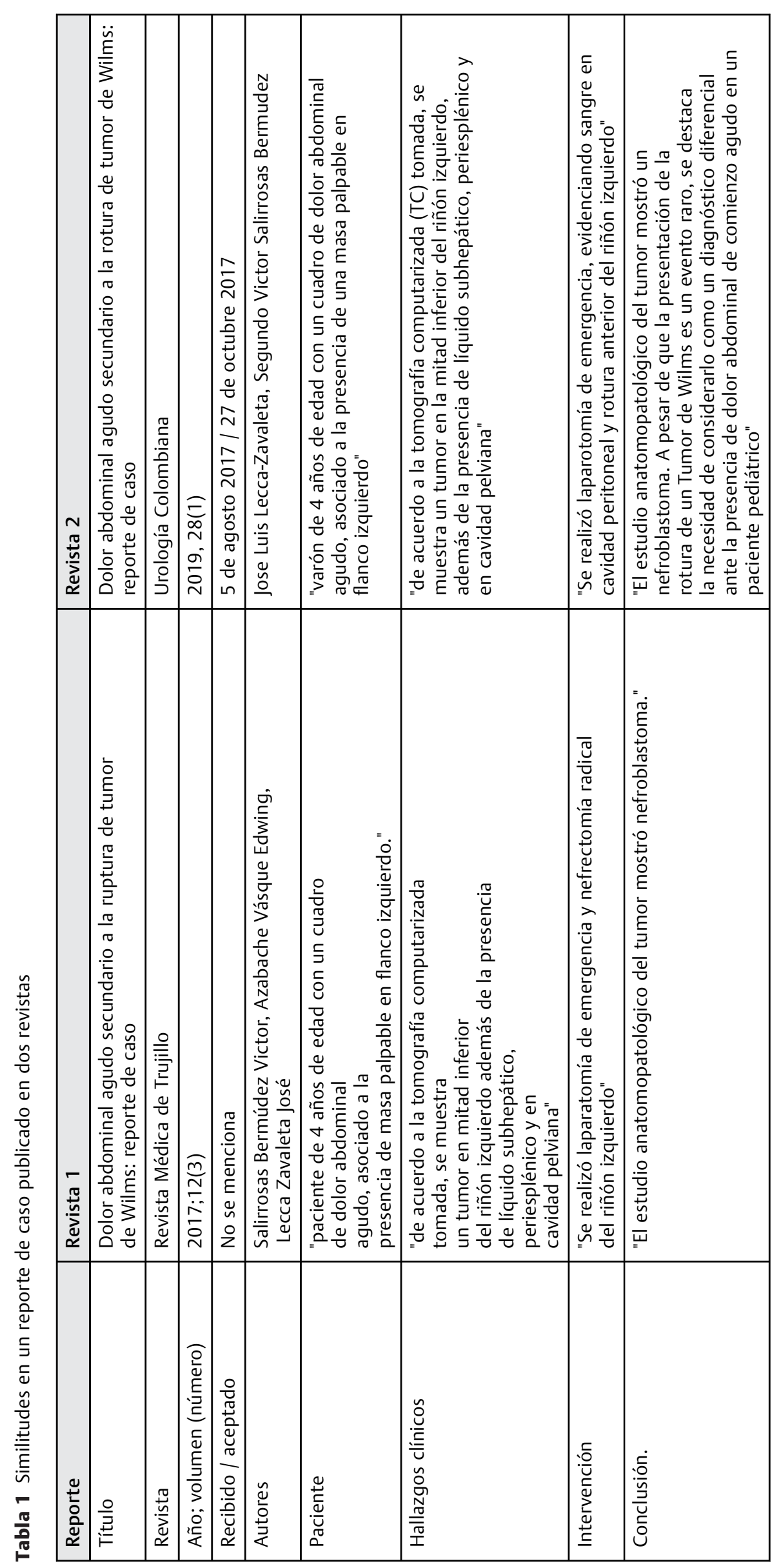

